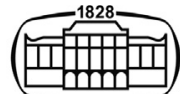

AKADÉMIAI KIADÓ

Journal of Behavioral Addictions

$10(2021) 4,901-911$

DOI:

$10.1556 / 2006.2021 .00073$

(c) 2021 The Author(s)

\section{FULL-LENGTH REPORT}

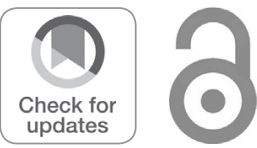

\title{
Changes in substance use and other reinforcing behaviours during the COVID-19 crisis in a general population cohort study of young Swiss men
}

\author{
JOSEPH STUDER $^{1 *}$ D, SIMON MARMET ${ }^{1}$ (D, \\ GERHARD GMEL $^{1,2,3,4} \odot$, MATTHIAS WICKI ${ }^{1} \odot$, \\ FLORIAN LABHART $^{2,5,6} \odot$, CÉLINE GACHOUD $^{1} \odot$, \\ JEAN-BERNARD DAEPPEN ${ }^{1} \odot$ and NICOLAS BERTHOLET ${ }^{1}$ \\ ${ }^{1}$ Addiction Medicine, Department of Psychiatry, Lausanne University Hospital and University of \\ Lausanne, Lausanne, Switzerland \\ ${ }^{2}$ Addiction Switzerland, Lausanne, Switzerland \\ ${ }^{3}$ Center for Addiction and Mental Health, Toronto, Ontario, Canada \\ ${ }^{4}$ University of the West of England, Bristol, United Kingdom \\ ${ }^{5}$ Idiap Research Institute, Martigny, Switzerland \\ ${ }^{6}$ La Trobe University, Melbourne, Australia
}

Received: March 8, 2021 - Revised manuscript received: September 10, 2021 - Accepted: October 3, 2021

Published online: October 27, 2021

\begin{abstract}
Background and Aims: There are concerns about the potential impact of the coronavirus disease (COVID-19) pandemic on substance use (SU) and other reinforcing behaviours (ORB). This paper investigates changes in SU and ORB among young men during the COVID-19 crisis (i.e. March-June 2020). Methods: Before and during the COVID-19 crisis, 2,344 young Swiss men completed questionnaires covering SU (i.e. alcohol, cigarettes, illegal cannabis), ORB (i.e. gaming, watching TV series, internet pornography) and sociodemographic and work-related characteristics (i.e. deterioration in the work situation, change in working hours, change in working hours from home, healthcare workers' and other professionals' contacts with potentially infected people, linguistic region, call up to military or civil protection unit, living situation, age). Results: Latent-change score models showed significant decreases of $17 \%$ for drinking volume and frequency of heavy episodic drinking, and a significant increase of $75 \%$ for time spent gaming and watching TV series. Subgroups showed greater relative increases. Frenchspeaking participants, those who experienced a deterioration in their work situation and healthcare workers in contact with potentially infected people reported increased cigarette use. Those without children increased gaming, whereas those who worked fewer hours, experienced a deterioration in their work situation or were French-speaking did more gaming and watched more TV series. Those who lived alone or were German-speaking watched more internet pornography. Conclusion: During the COVID-19 crisis, young Swiss men drank less alcohol and spent more time gaming and watching TV series. Changes in SU and ORB were not homogenous in the young Swiss men population.
\end{abstract}

\section{KEYWORDS}

substance use, other reinforcing behaviours, COVID-19, cohort study on substance use risk factors, young men, Switzerland

Corresponding author.

\section{INTRODUCTION}

The coronavirus disease (COVID-19) pandemic had a major impact on everyday life in Switzerland. This global health crisis' first wave and the government measures implemented 
to limit the virus' propagation had the potential to significantly affect individuals' health behaviours, notably the use of alcohol, other substances and other reinforcing behaviours. The Swiss Federal Council introduced measures to limit the propagation of the severe acute respiratory syndrome coronavirus 2 (SARS-COV-2) on 16 and 20 March 2020 (Swiss Federal Council, 2020a, b). These included closing borders, schools, nurseries, bars, and non-essential shops, severe limitations on restaurant opening, physical distancing measures ( $\geq$ two meters distance, bans on gatherings of $>$ five people), and health and safety measures in supermarkets (distancing, limited numbers of shoppers admitted simultaneously). People were also recommended to stay at home, work from home and avoid public transportation. These measures led to fewer hours worked and to increases in the unemployment rate among significant segments of the workforce (Faber, Ghisletta, \& Schmidheiny, 2020). On 16 March 2020, Switzerland had registered 43.9 cumulative confirmed cases per 100,000 inhabitants. In Switzerland, about $71 \%$ of the population lives in the German-speaking, 24\% in the French-speaking and 5\% in the Italian- or Romansch-speaking regions (Swiss Federal Office of Statistics, 2016). The prevalence of confirmed cases was more than three times greater in French- and Italian- or Romansch-speaking regions than in German-speaking ones (Swiss Federal Office of Public Health, 2020). On that date, Switzerland was among the top 9 countries worldwide with the highest numbers of cumulative confirmed cases (World Health Organization (WHO), 2020).

Although anecdotal media reports stated that alcohol (Blum, 2020; Wilson, 2020) and tobacco (Bonzom, 2020) sales increased at the start of the COVID-19 crisis, it was unclear whether these reports reflected real increases in the use of both substances and how these behaviours would evolve in the long run. Border and bar closures combined with an economic downturn may have reduced the availability (including accessibility) of alcohol (Rehm et al., 2020) and social opportunities to use it. The same may be true for other substances. For example, cannabis (with a concentration of tetrahydrocannabinol [THC] $\geq 1 \%$ ) is illegal in Switzerland, and smuggling from abroad is an important source for the domestic illegal market (Zobel, Esseiva, Udrisard, \& Samitca, 2020). As availability is an important factor of demand (Gmel, Holmes, \& Studer, 2016), this could have reduced substance use in the general population. However, experience from previous and current crises suggests that the pandemic may have induced stress and anxiety (Ahorsu et al., 2020; Brooks et al., 2020; Lau et al., 2005; Marmet et al., 2021a), at least for some population subgroups, such as those who lost their jobs, faced major changes in their work situation, were socially isolated, or were healthcare and essential workers (Brooks et al., 2020; Centers for Disease Control and Prevention, 2020; Marmet et al., 2021). In line with the stress-response-dampening theory (Sayette, 1999; Sher, Bartholow, Peuser, Erickson, \& Wood, 2007; Sher \& Levenson, 1982), distress may lead individuals to increase their substance use to relieve stress and reduce anxiety. This is supported by results showing positive associations between COVID-19 related stress and substance use (Callinan et al., 2021; Rolland, Haesebaert, Zante, Benyamina, \& Haesebaert, 2020; Taylor, Paluszek, Rachor, McKay, \& Asmundson, 2021). There were also anecdotal media and industry reports of the increased involvement in other reinforcing behaviours, such as social media, gaming, internet pornography and TV series, from the start of the first wave of the COVID-19 crisis (La Presse.ca, 2020; Mestre-Bach, Blycker, \& Potenza, 2020; M. Perez, 2020; S. Perez, 2020; Schultz, 2020; Shanley, 2020). This may have been a consequence of burden, stress and anxiety caused by COVID-19 (Brailovskaia \& Margraf, 2021; Rolland et al., 2020; Zhao \& Zhou, 2021), and of the increased availability of digital activities during the crisis. For example, the internet pornography industry seems to have seized upon the situation to offer free content for a limited time (Mestre-Bach et al., 2020). Reduced working hours and government recommendations to stay at home may also have increased the time available for these activities.

To date, studies investigating the impacts of the COVID-19 crisis on substance use yielded no consistent pattern of change. Regarding alcohol and cigarette use, some studies indicated increased use during the COVID-19 crisis (Ahmed et al., 2020; Lechner et al., 2020; Rolland et al., 2020; Stanton et al., 2020; Vanderbruggen et al., 2020), whereas other suggested decreased use (Bade et al., 2020; Caponnetto et al., 2020; Scarmozzino \& Visioli, 2020). One study of illegal cannabis use found no significant change during the COVID-19 crisis (Vanderbruggen et al., 2020), whereas another showed a significant decrease in prevalence of use but a significant increase in the frequency of use (Dumas, Ellis, \& Litt, 2020). Regarding other reinforcing behaviours, existing studies have shown increased time spent watching screens, e.g., gaming, watching TV and pornography, video streaming, using social media and internet (Alomari, Khabour, \& Alzoubi, 2020; Balhara, Kattula, Singh, Chukkali, \& Bhargava, 2020; Burhamah et al., 2020; Cellini, Canale, Mioni, \& Costa, 2020; Lemenager et al., 2021; Luo, Chen, \& Liao, 2021; Mestre-Bach et al., 2020; Paschke, Austermann, Simon-Kutscher, \& Thomasius, 2021; Rolland et al., 2020; Sallie, Ritou, Bowden-Jones, \& Voon, 2021).

One major limitation of the existing literature is that most studies used either retrospective measures (e.g. Lechner et al., 2020) or subjective perceptions of changes in use (e.g. perceived increase, decrease, no change) during the COVID-19 crisis (e.g. Scarmozzino \& Visioli, 2020): they failed to measure participants' pre-pandemic levels. This may have introduced bias into their estimations of impact, making conclusions about changes at the individual level impossible.

To fill these gaps, we took advantage of the fourth and final wave of data collection from the Cohort study on Substance-Use Risk Factors (C-SURF), which ended just before the start of the COVID-19 crisis in Switzerland. Participants were asked to complete an additional questionnaire during the first wave of infection, allowing an assessment of potential changes in substance use and other reinforcing behaviours among young Swiss men. 


\section{Aims and hypotheses}

The study's first aim was to assess changes in alcohol (frequency of heavy episodic drinking and volume), cigarette, illegal cannabis use, gaming, and watching TV series and internet pornography during the COVID-19 crisis. We hypothesized changes to mirror changes in availability: decreases in substance use (alcohol, cigarettes, illegal cannabis) due to reduced availability and increases in other reinforcing behaviours (gaming, TV series, internet pornography) due to increased availability.

However, as mentioned above, the COVID-19 crisis could have triggered stress, anxiety and isolation, increased spare time and interfered with the daily lives of certain subgroups of the population. Consequently, substance use and other reinforcing behaviours may have increased in these subgroups. Accordingly, the study's second aim was to investigate whether the COVID-19 crisis affected substance use and other reinforcing behaviours differentially in certain cohort subgroups. Specifically, those who had lost their job or had major changes in their work situation, and those who were socially isolated or had more spare time (e.g. living alone, being childless), were hypothesized to report increases in both substance use and other reinforcing behaviours. Healthcare and essential workers were hypothesized to report increases in substance use, but not necessarily increases in other reinforcing behaviours, as they would not have had an abundance of spare time. When the questionnaire was being answered, Switzerland's German-speaking regions were less affected by COVID-19 than Frenchspeaking regions (Swiss Federal Office of Public Health, 2020), despite the implementation of identical measures to limit the virus' propagation. Thus, the German-speaking subgroup may have been less subject to the stress of being infected or infecting others. We therefore hypothesized changes in substance use and other reinforcing behaviours to be smaller among German-speakers than among Frenchspeakers.

\section{METHODS}

\section{Participants}

Participants came from C-SURF, a general populationbased cohort of young Swiss men started in 2010. Between 1 April 2019 and 14 February 2020, 4,407 participants completed the fourth and final online C-SURF questionnaire (the pre-COVID-19 assessment). They were subsequently all invited by email to complete an additional online questionnaire (the COVID-19 assessment). Between 13 May and 8 June 2020, 2,344 (53.2\%) participants completed at least two-thirds of the questionnaire, including the questions on substance use and other reinforcing behaviours, and sociodemographic and workrelated characteristics used in the present study. Full details on the C-SURF study and participants recruitment can be found in Supplementary Material S1.

Sample characteristics are reported in Table 1.

\section{Measures}

Substance use and other reinforcing behaviours. Both assessments (pre-COVID-19 and COVID-19) used the same questions to ask participants about their substance use and other reinforcing behaviours, except for the period of reference: "in the previous 12 months" for the pre-COVID-19 assessment, and "since the start of the COVID-19 measures" for the COVID-19 assessment. All variables were coded to reflect weekly use: weekly drinking volume and number of cigarettes smoked, weekly time spent gaming, and watching TV series and internet pornography were computed as the product of quantity and frequency of use. For heavy episodic drinking (HED; drinking six or more standard drinks on one

Table 1. Sample characteristics $(n=2,344)$

\begin{tabular}{|c|c|c|c|}
\hline \multicolumn{4}{|l|}{ Age Before COVID-19 } \\
\hline $\mathrm{M}, \mathrm{SD}, n$ missing & 28.20 & 1.27 & 0 \\
\hline Range & \multicolumn{3}{|c|}{$25.65 ; 34.97$} \\
\hline \multicolumn{4}{|l|}{ Age During COVID-19 } \\
\hline $\mathrm{M}, \mathrm{SD}, n$ missing & 29.07 & 1.27 & 0 \\
\hline Range & \multicolumn{2}{|c|}{$26.54 ; 35.84$} & \\
\hline \multicolumn{3}{|l|}{ Change in working hours ( $n$ missing) } & 0 \\
\hline Increase $(n, \%)^{\mathrm{a}}$ & 159 & 6.8 & \\
\hline Almost no change $(n, \%)^{\mathrm{b}}$ & 1,511 & 64.5 & \\
\hline Decrease $(n, \%)^{c}$ & 674 & 28.8 & \\
\hline \multicolumn{3}{|l|}{$\begin{array}{l}\text { Change in working hours at home } \\
(n \text { missing })\end{array}$} & 38 \\
\hline Increase $(n, \%)^{\mathrm{a}}$ & 948 & 41.1 & \\
\hline Almost no change $(n, \%)^{\mathrm{b}}$ & 1,222 & 53.0 & \\
\hline Decrease $(n, \%)^{c}$ & 136 & 5.9 & \\
\hline \multicolumn{3}{|l|}{$\begin{array}{l}\text { Deterioration in work situation } \\
\quad(n \text { missing })\end{array}$} & 13 \\
\hline Yes $(n, \%)$ & 492 & 21.1 & \\
\hline No $(n, \%)$ & 1,839 & 78.9 & \\
\hline \multicolumn{3}{|c|}{$\begin{array}{l}\text { Healthcare worker in contact with potentially infected } \\
\text { people ( } n \text { missing) }\end{array}$} & 5 \\
\hline Yes $(n, \%)$ & 110 & 4.7 & \\
\hline No $(n, \%)$ & 2,229 & 95.3 & \\
\hline \multicolumn{3}{|c|}{$\begin{array}{l}\text { Other worker in contact with potentially infected people } \\
(n \text { missing })\end{array}$} & 2 \\
\hline Yes $(n, \%)$ & 544 & 23.2 & \\
\hline No $(n, \%)$ & 1,798 & 76.8 & \\
\hline \multicolumn{3}{|l|}{$\begin{array}{l}\text { Called up for military or civil service } \\
(n \text { missing })\end{array}$} & 1 \\
\hline Yes $(n, \%)$ & 245 & 10.5 & \\
\hline No $(n, \%)$ & 2,098 & 89.5 & \\
\hline \multicolumn{3}{|l|}{ Being a father ( $n$ missing) } & 9 \\
\hline Yes $(n, \%)$ & 271 & 11.6 & \\
\hline No $(n, \%)$ & 2,064 & 88.4 & \\
\hline \multicolumn{3}{|l|}{ Living alone ( $n$ missing) } & 0 \\
\hline Yes $(n, \%)$ & 511 & 21.8 & \\
\hline No $(n, \%)$ & 1,833 & 78.2 & \\
\hline \multicolumn{3}{|l|}{ Linguistic region ( $n$ missing) } & 0 \\
\hline French $(n, \%)$ & 1,364 & 58.2 & \\
\hline German $(n, \%)$ & 980 & 41.8 & \\
\hline
\end{tabular}

Note. M: Mean. SD: Standard deviation. ${ }^{\text {a, }}{ }^{\mathrm{c}}>4 \mathrm{~h}$ a week. ${ }^{\mathrm{b}}$ between -4 and $+4 \mathrm{~h}$ a week. 
occasion) and illegal cannabis ( $\geq 1 \%$ THC), frequency of use were assessed.

Sociodemographic and work-related characteristics. Changes in total working hours and hours worked from home were measured as the difference between before and after the introduction of national-level COVID-19 measures. Differences were recoded into fewer working hours (minus $4 \mathrm{~h}$ or more a week), almost no change (change of less than plus or minus $4 \mathrm{~h}$ a week), and more working hours (plus $4 \mathrm{~h}$ or more a week).

Deterioration in work situation was measured by asking whether a participant's work situation had changed since the start of the COVID-19 measures. Response options were "I was/am unemployed because of COVID-19", "I was/have been temporarily laid off (i.e. partial/temporary unemployment)", "I am self-employed and have lost money because of COVID-19", and "My work situation has not changed much". Responses were recoded to reflect a deterioration in work situations (being unemployed, temporarily laid off, and losing money vs no change).

Participants were also asked whether they worked in healthcare or another sector potentially in contact with infected people, whether they were called up to their military or civil protection units in response to the COVID-19 crisis, whether they had children, and whether they lived alone. Participants' age during COVID-19 crisis and whether they lived in a German- or French-speaking region were also assessed.

A detailed description of the measures used can be found in Supplementary Material S1.

\section{Statistical analyses}

The sample's descriptive statistics were calculated. Changes in substance use and other reinforcing behaviours, correlations between changes, and associations of changes with sociodemographic and work-related characteristics were analysed using latent change score models (LCS; McArdle, 2009) in Mplus 8.3 software (Muthén \& Muthén, 1998-
2017). Bootstrap (5,000 draws) and 95\% bias-corrected percentile bootstrap confidence intervals were used to account for potentially skewed distributions. When significant associations of changes in substance use and other reinforcing behaviours with sociodemographic and work-related characteristics were found, a simple slope analysis was used to test the significance of changes in each subgroup (Aiken \& West, 1991). LCS modelling used the responses of participants who had completed at least two-thirds of the COVID19 assessment $(n=2,344)$. Of these, 151 (6.4\%) participants had a missing value on at least one item. These missing values were handled using full information maximum likelihood (FIML). Non-respondents (questionnaire not completed or less than two-thirds completed) had significantly higher scores on pre-COVID-19 cigarette and illegal cannabis use than did respondents (questionnaire at least two-thirds completed) to the COVID-19 assessment (see Supplementary Table S2). As a sensitivity analysis, LCS were also tested on the total sample ( $n=4,407$; including all nonrespondents), and missing data were handled using FIML.

\section{Ethics}

The study protocol was approved by the Human Research Ethics Committee of the Canton of Vaud (15/07, PB_201800296).

\section{RESULTS}

Means and standard deviations of substance use and other reinforcing behaviours before and during COVID-19 crisis are reported in Table 2. Results of LCS investigating changes in substance use and other reinforcing behaviours are reported in Table 3 (for sensitivity analysis see Supplementary Table S3). Results showed significant decreases in weekly drinking volume $(-1.15$ standard drinks/week, $16.8 \%$ decrease) and frequency of HED (-0.05 days / week, 17.7\% decrease) during the COVID-19 crisis, compared to the pre-

Table 2. Substance use and other reinforcing behaviours before and during COVID-19 crisis $(n=2,344)$

\begin{tabular}{|c|c|c|c|c|c|c|}
\hline & \multicolumn{3}{|c|}{ Before COVID-19 } & \multicolumn{3}{|c|}{ During COVID-19 } \\
\hline & M & SD & missing $(n)$ & M & $\mathrm{SD}$ & $\operatorname{missing}(n)$ \\
\hline \multicolumn{7}{|l|}{ Substance-related addictive behaviours } \\
\hline $\begin{array}{l}\text { Drinking volume (weekly number of } \\
\text { standard drinks) }\end{array}$ & 6.83 & 12.45 & 1 & 5.69 & 9.73 & 7 \\
\hline $\begin{array}{l}\text { Heavy episodic drinking (weekly } \\
\text { frequency) }\end{array}$ & 0.26 & 0.57 & 0 & 0.21 & 0.62 & 4 \\
\hline Cigarettes (weekly number) & 16.51 & 38.35 & 0 & 15.70 & 39.26 & 0 \\
\hline $\begin{array}{l}\text { Illegal cannabis use (weekly } \\
\text { frequency) }\end{array}$ & 0.33 & 1.23 & 0 & 0.35 & 1.33 & 0 \\
\hline \multicolumn{7}{|l|}{ Other reinforcing behaviours } \\
\hline Gaming (hours per week) & 4.10 & 7.42 & 0 & 7.18 & 11.08 & 1 \\
\hline Watching TV series (hours per week) & 4.73 & 6.02 & 1 & 8.28 & 9.07 & 2 \\
\hline $\begin{array}{l}\text { Watching internet pornography } \\
\text { (hours per week) }\end{array}$ & 4.60 & 7.09 & 0 & 4.82 & 8.21 & 17 \\
\hline
\end{tabular}

Note. $\mathrm{M}=$ Mean. $\mathrm{SD}=$ Standard deviation. 
Table 3. Estimated change in substance use and other reinforcing behaviours from before to during the COVID-19 crisis based on latent change score model and percentage of change $(n=2,344)$

\begin{tabular}{|c|c|c|c|c|}
\hline \multirow[b]{2}{*}{ Change in } & \multirow[b]{2}{*}{ Estimate } & \multicolumn{2}{|c|}{$\begin{array}{l}\text { Bias-corrected percentile } \\
\text { bootstrap confidence } \\
\text { intervals }\end{array}$} & \multirow[b]{2}{*}{$\%$ change } \\
\hline & & $2.5 \%$ & $97.5 \%$ & \\
\hline $\begin{array}{l}\text { Weekly drinking volume } \\
\text { ( } n \text { standard drinks) }\end{array}$ & -1.15 & -1.55 & -0.80 & $-16.8 \%$ \\
\hline $\begin{array}{l}\text { Weekly frequency of heavy episodic } \\
\text { drinking }\end{array}$ & -0.05 & -0.08 & -0.02 & $-17.7 \%$ \\
\hline Weekly number of cigarettes ${ }^{\mathrm{a}}$ & -0.81 & -1.78 & 0.18 & $4.9 \%$ \\
\hline $\begin{array}{l}\text { Weekly frequency of illegal cannabis } \\
\text { use }\end{array}$ & 0.02 & -0.01 & 0.05 & $6.4 \%$ \\
\hline Weekly hours spent gaming & 3.08 & 2.76 & 3.43 & $75.3 \%$ \\
\hline Weekly hours spent watching TV series & 3.55 & 3.23 & 3.88 & $75.0 \%$ \\
\hline $\begin{array}{l}\text { Weekly hours spent watching internet } \\
\text { pornography }\end{array}$ & 0.23 & -0.05 & 0.51 & $4.7 \%$ \\
\hline
\end{tabular}

Note. Coefficients in bold are significant according to bias-corrected $2.5 \%$ and $97.5 \%$ percentile bootstrap confidence intervals. ${ }^{\text {a }}$ This change is significant in the sensitivity analysis (see Table S3).

COVID-19 period. In contrast, significant increases were found for time spent gaming $(+3.08 \mathrm{~h} /$ week, $75.3 \%$ increase) and watching TV series $(+3.55 \mathrm{~h} /$ week, $75.0 \%$ increase). Weekly cigarettes smoked slightly decreased, whereas the frequency of illegal cannabis use and time spent watching internet pornography increased slightly, but these changes were not significant. Correlations between changes in substance use and other reinforcing behaviours were generally positive (Table 4; for sensitivity analysis see Supplementary Table S4) but weak, and only about onethird was statistically significant.

Associations of changes in substance use and other reinforcing behaviours with sociodemographic and workrelated characteristics are reported in Table 5 (for sensitivity analysis see Supplementary Table S5). The coefficients in Table 5 reflect relative changes, i.e. positive values indicate larger increases or smaller decreases, whereas negative values indicate larger decreases or smaller increases than the reference group. For the sociodemographic and work-related characteristics significantly associated with changes, simple slopes (not reported in Table 5) were also tested in the reference category and the contrasted groups.

Fewer working hours (vs almost no change) was significantly associated with increased time spent gaming and watching TV series. Simple slope analysis showed that participants who reported fewer working hours or almost no change in working hours both spent significantly more time gaming and watching TV series. However, increases were larger among those who worked fewer hours than among those reporting almost no change in working hours, both for gaming (mean [bias corrected $2.5 \%, 97.5 \%$ percentile bootstrap confidence interval $]=4.04[3.39,4.76]$ vs $2.67[2.27$, $3.08])$ and for watching TV series $(4.62[3.96,5.30]$ vs 3.22 $[2.82,3.62])$.

Deterioration in work situation was significantly associated with changes in cigarette use, time spent gaming and watching TV series. Simple slope analysis showed that those reporting no deterioration in their work situation

Table 4. Correlations between changes in substance use and other reinforcing behaviours based on a latent change score model $(n=2,344)$

\begin{tabular}{|c|c|c|c|c|c|c|}
\hline & $\begin{array}{c}2 . \\
\text { Weekly } \\
\text { frequency of } \\
\text { heavy episodic } \\
\text { drinking }\end{array}$ & $\begin{array}{c}3 . \\
\text { Weekly } \\
\text { number } \\
\text { of } \\
\text { cigarettes }\end{array}$ & $\begin{array}{c}4 . \\
\text { Weekly } \\
\text { frequency of } \\
\text { illegal } \\
\text { cannabis use }\end{array}$ & $\begin{array}{c}5 . \\
\text { Weekly } \\
\text { hours } \\
\text { spent } \\
\text { gaming }\end{array}$ & $\begin{array}{c}6 . \\
\text { Weekly hours } \\
\text { spent } \\
\text { watching TV } \\
\text { series }\end{array}$ & $\begin{array}{c}7 . \\
\text { Weekly hours } \\
\text { spent watching } \\
\text { internet } \\
\text { pornography }\end{array}$ \\
\hline 1. Weekly drinking volume & 0.31 & 0.14 & 0.08 & -0.02 & 0.00 & 0.10 \\
\hline $\begin{array}{l}\text { 2. Weekly frequency of heavy episodic } \\
\text { drinking }\end{array}$ & & 0.05 & 0.09 & 0.01 & 0.01 & 0.07 \\
\hline 3. Weekly number of cigarettes & & & 0.00 & 0.01 & 0.11 & 0.01 \\
\hline 4. Weekly frequency of illegal cannabis use & & & & 0.01 & 0.08 & 0.05 \\
\hline 5. Weekly hours spent gaming & & & & & 0.10 & 0.08 \\
\hline 6. Weekly hours spent watching TV series & & & & & & 0.01 \\
\hline $\begin{array}{l}\text { 7. Weekly hours spent watching internet } \\
\text { pornography }\end{array}$ & & & & & & \\
\hline
\end{tabular}

Note. Correlations in bold are significant according to bias-corrected $2.5 \%$ and $97.5 \%$ percentile bootstrap confidence intervals (not shown). 


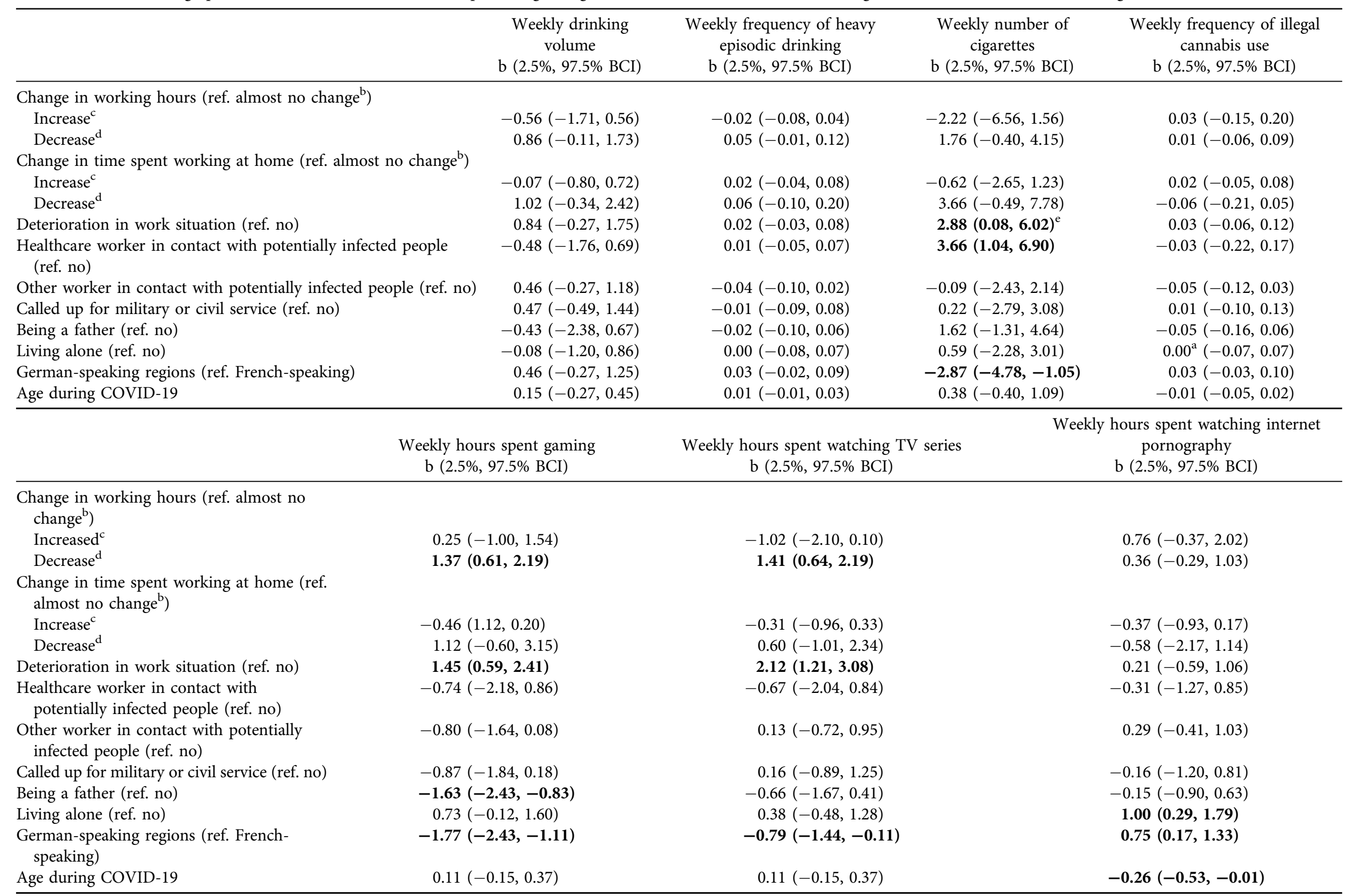

Note. Ref. $=$ reference. $\mathrm{B}=$ coefficient of association. $\mathrm{BCI}=$ bias-corrected percentile bootstrap confidence intervals. Coefficients in bold are significant according to BCI. ${ }^{\mathrm{a}}$ before rounding $=$ -0.002 . between -4 and $+4 \mathrm{~h}$ a week. ${ }^{c, d}>4 \mathrm{~h}$ a week. ${ }^{\mathrm{e}}$ this coefficient is not significant in the sensitivity analysis. 
significantly decreased their cigarette use $(-1.42[-2.40$, -0.45]), whereas those who reported a deterioration increased their use, although not significantly (1.39 [-1.13, $4.51])$. Those reporting deterioration in their work situation increased their time spent gaming more than those reporting no deterioration $(4.23[3.42,5.13]$ vs $2.78[2.43,3.13])$ and watching TV series $(5.22[4.40,6.17]$ vs $3.10[2.77,3.46])$.

Being a healthcare worker in contact with potentially infected people was significantly associated with changes in cigarette use. Simple slope analysis showed that they significantly increased their cigarette use $(2.68[0.28,5.73])$, whereas healthcare workers not in contact with potentially infected people and other workers or the unemployed decreased their use, although not significantly $(-0.98[-1.98$, $0.05])$.

Some household conditions were also associated with changes in other reinforcing behaviours. Being a father was significantly associated with changes in time spent gaming. Simple slope analysis showed that fathers increased their time spent gaming less than childless men $(1.64[0.96,2.42]$ vs $3.27[2.92,3.65])$. Living alone was significantly associated with changes in time spent watching internet pornography. Simple slope analysis showed that watching internet pornography increased significantly among those living alone $(1.01[0.36,1.72])$ and non-significantly among those not living alone $(0.02[-0.30,0.33])$.

Living in German-speaking regions (vs French-speaking) was significantly associated with changes in cigarette use, time spent gaming, and watching TV series and internet pornography. Simple slope analysis showed that respondents in German-speaking regions (but not French-speaking region) significantly decreased their cigarette use (-2.48 [-3.81, $-1.26]$ vs $0.39[-0.98,1.82])$ and significantly increased their time spent watching internet pornography $(0.67[0.21,1.14]$ vs $-0.08[-0.43,0.26])$. Living in French-speaking regions (vs German-speaking) was associated with a larger increase in time spent gaming $(3.83[3.34,4.30]$ vs $2.05[1.62,2.52])$ and watching TV series $(3.88[3.44,4.34]$ vs $3.09[2.62,3.58])$. Finally, age was significantly associated with a relative decrease in watching internet pornography.

\section{DISCUSSION}

The present study aimed to assess changes in substance use and other reinforcing behaviours in a large sample of young men from before to during the first wave of the COVID-19 crisis in Switzerland and to investigate whether this affected substance use and other reinforcing behaviours differentially in certain subgroups. Results showed significant decreases of approximately $17 \%$ for drinking volume and HED frequency. These reported changes may reflect the immediate impact of COVID-19 measures on the availability of alcohol (Rehm et al., 2020). Since alcohol use is one of the main risk factor for mortality and morbidity (Rehm, Taylor, \& Room, 2006) and HED is one of the strongest predictor of alcoholrelated harm, e.g. blackouts, accidents, problem with the police, violence, among young adults (Gmel, Rehm, \&
Kuntsche, 2003; Wechsler, Davenport, Dowdall, Moeykens, \& Castillo, 1994), a decrease in alcohol use is good news for public health. The open question is whether this decrease will be maintained over time. As opposed to alcohol use, significant increases of approximately $75 \%$ more time spent gaming and watching TV series were found. This result may reflect participants' increased free time and the availability of special offers during the COVID-19 crisis, as well as the engagement in these activities as coping mechanisms in response to the increased stress and burden caused by the COVID-19 crisis. High involvement in such activities is not problematic by itself (at least for gaming; Király, Tóth, Urbán, Demetrovics, \& Maraz, 2017). Gaming may even be beneficial to relieve stress, reduce loneliness and increase well-being in general (Johannes, Vuorre, \& Przybylski, 2021; Johnson, Jones, Scholes, \& Carras, 2013; Kaye, Kowert, \& Quinn, 2017; Reinecke, 2009). This was also found in the context of the COVID-19 crisis (Barr \& Copeland-Stewart, 2021). Thus, moderate increase in time spent gaming and watching TV series may be an adaptive response to the changes in daily routines and stress caused by the crisis. However, for a minority of users, high involvement may progress into long-lasting problematic patterns of use. Professionals and policymakers may play a role to limit involvement in these activities by providing recommendations. As proposed by Király et al. (2020), these may include making a schedule of daily activities to keep a daily routine, the maintenance of a healthy lifestyle (e.g. regular physical activity, regular sleep, healthy food) and of social activities with family members and social interactions, the use of relaxation techniques and digital wellbeing apps, the awareness and regulation of one's screen time, and seeking help from professionals or help lines if needed.

Changes in substance use and other reinforcing behaviours did not happen uniformly throughout the sample population. Thus, particular attention should be paid to subgroups who did increase their use. Working less or experiencing a deterioration in one's work situation was associated with greater increases in time spent gaming and watching TV series. Consistent with the results of Rolland et al. (2020), showing that unemployment was associated with increased screen use, this finding may reflect the lack of social activities available due to COVID-19 measures, combined with more time available and the extra stress of being unemployed or partly unemployed during a lockdown. Those reporting no deterioration in their work situation were also found to have decreased cigarette use, whereas those reporting a deterioration did not change their cigarette use significantly. This relative increase was consistent with the results of Compton, Gfroerer, Conway, and Finger (2014), who showed that unemployment was associated with cigarette use.

Healthcare workers in contact with potentially infected people reported increased cigarette use whereas others did not change significantly their use. During the SARS outbreak starting in 2002, about $20 \%$ of all individuals infected were healthcare workers (World Health Organization (WHO), 2003). Thus, healthcare workers may suffer from higher 
levels of anxiety and stress because of increased workloads and fears of infection and may increase their use of cigarettes as a coping mechanism. No significant increase in alcohol use was found in this subgroup. However, given the evidence of an increase in alcohol use disorders prevalence among healthcare workers three years after the SARS outbreak (Wu et al., 2008), studying the COVID-19 pandemic's long-term impact on substance use will be important.

Fathers increased their time spent gaming by less than childless participants. During lockdown, fathers spent more time on childcare because nurseries and schools were closed, grandparents were recommended not to look after children, and children were at home. Childless participants almost certainly had more free time available for gaming. Furthermore, participants living alone watched more internet pornography, whereas viewing by others did not change significantly. Being forced to stay at home during lockdown, social interactions and activities were particularly limited for those living alone, and they were likely more prone to social isolation (Marmet et al., 2021). They may have watched more internet pornography to pass the time and to counter potential decreases in their real-life sexual activity.

Participants living in French-speaking regions increased their time spent gaming and watching TV series by more than those living in German-speaking regions did. They also decreased their cigarette use by less than participants living in German-speaking regions. German speakers also showed a bigger increase in internet pornography, which had already been found to be more prevalent in Germanspeaking than in French-speaking regions before the COVID-19 crisis (Studer, Marmet, Wicki, \& Gmel, 2019). Thus, with the exception of internet pornography, differences between linguistic regions may reflect the fact that French-speaking regions were more seriously affected by the first wave of the COVID-19 crisis than were Germanspeaking regions.

This study is not without limitations. The sample included only young Swiss men and results are thus not directly generalizable to other age groups, women or other countries. Using self-reported questionnaires may introduce biases such as social desirability or recall bias. Also, because the C-SURF pre-COVID assessment was spread out over almost a year, participants had different time intervals between their pre-COVID and COVID assessments. Despite only about $50 \%$ of the participants invited to answer the COVID-study doing so, results from our sensitivity analysis, including all non-respondents, yielded the same patterns of change (although the significance of two coefficients differed from the main analyses). Also, although reported changes in substance use and other reinforcing behaviours could be attributed to the COVID-19 crisis, they could partly reflect seasonal changes or personal developmental changes. The present study's strengths include its large, non-selective sample. More importantly, it did not rely on retrospective pre-COVID period reports, as measures of substance use and other reinforcing behaviours from C-SURF were available.
To conclude, the present study suggests that, during the first wave of the COVID-19 crisis (until June 2020), there was a decrease in alcohol use (but not in cigarette or illegal cannabis use) and more time was spent on other reinforcing behaviours such as gaming or watching TV series (but not internet pornography). Substance use and other reinforcing behaviours increased more in some sample subgroups that were found to experience higher levels of psychological distress during the COVID-19 crisis (Marmet et al., 2021): those reporting changes in their work situation (deterioration, fewer working hours, more time spent working from home), healthcare workers in contact with potentially infected people, the childless or those living alone. These specific changes corroborated the hypothesis that substance use and other reinforcing behaviours were not only more likely to occur if they were available but also that may have served as a coping strategy if individuals experienced heightened stress and isolation during the crisis. One open question is whether these changes will persist, increase or decrease over time. This will depend on further developments in the COVID-19 pandemic, the measures taken to combat it, the occurrence and magnitude of the expected economic downturn, and potential changes in the socio-cultural landscape affecting the usage contexts of different substance and other reinforcing behaviours. Although this initial decrease in alcohol use is good news for public health, caution is warranted because substance use may increase in the wake of the postCOVID economic recession expected to occur in many countries. Close monitoring of further developments in substance use is thus recommended. As regards growing digital activities, efforts to prevent their progression to chronic patterns of excessive use (including addictions) may be needed.

Funding sources: Swiss National Science Foundation (FN 33CSC0-122679, FN 33CS30_139467, FN 33CS30_148493 and FN 33CS30_177519).

Authors' contribution: Study concept and design (JS, NB, GG, JBD), data collection (CG, FL) statistical analyses and draft of the manuscript (JS, NB, SM), interpretation of data (JS, NB, GG; SM, MW, CG, FL, JBD), principal investigator of the C-SURF project (GG), critical review of the manuscript (JS, NB, CG, SM, MW, FL, JBD, GG). All authors had full access to all the study data and accept responsibility for data integrity and analytical accuracy.

Conflict of interests: The authors declare no conflict of interest.

\section{SUPPLEMENTARY MATERIAL}

Supplementary data to this article can be found online at https://doi.org/10.1556/2006.2021.00073. 


\section{REFERENCES}

Ahmed, M. Z., Ahmed, O., Aibao, Z., Hanbin, S., Siyu, L., \& Ahmad, A. (2020). Epidemic of COVID-19 in China and associated psychological problems. Asian Journal of Psychiatry, 51, 102092. https://doi.org/10.1016/j.ajp.2020.102092.

Ahorsu, D. K., Lin, C.-Y., Imani, V., Saffari, M., Griffiths, M. D., \& Pakpour, A. H. (2020). The fear of COVID-19 scale: Development and initial validation. International Journal of Mental Health and Addiction. https://doi.org/10.1007/s11469-02000270-8.

Aiken, L. S., \& West, S. G. (1991). Multiple regression: Testing and interpreting interactions. Newbury Park: Sage.

Alomari, M. A., Khabour, O. F., \& Alzoubi, K. H. (2020). Changes in physical activity and sedentary behavior amid confinement: The BKSQ-COVID-19 project. Risk Management and Healthcare Policy, 13, 1757-1764. https://doi.org/10.2147/RMHP. S268320.

Bade, R., Simpson, B. S., Ghetia, M., Nguyen, L., White, J. M., \& Gerber, C. (2020). Changes in alcohol consumption associated with social distancing and self-isolation policies triggered by COVID-19 in South Australia: A wastewater analysis study. Addiction, 116(6), 1600-1605. https://doi.org/10.1111/add. 15256.

Balhara, Y., Kattula, D., Singh, S., Chukkali, S., \& Bhargava, R. (2020). Impact of lockdown following COVID-19 on the gaming behavior of college students. Indian Journal of Public Health, 64(6), 172-176. https://doi.org/10.4103/ijph.IJPH_465_ 20.

Barr, M., \& Copeland-Stewart, A. (2021). Playing video games during the COVID-19 pandemic and effects on players' wellbeing. Games and Culture, 15554120211017036. https://doi.org/ 10.1177/15554120211017036.

Blum, G. (2020). Mit Schnaps durch die Krise? [Through the crisis with booze?]. Retrieved from https://www.blick.ch/news/ politik/schweizer-kaufen-mehr-alkohol-mit-schnaps-durchdie-krise-id15828739.html.

Bonzom, N. (2020). Coronavirus en Occitanie : Avec la fermeture de la frontière avec l'Espagne, les ventes de cigarettes explosent côté français [Coronavirus in Occitania: With the closure of the border with Spain, cigarette sales explode on the French side]. Retrieved from https://www.20minutes.fr/societe/275637120200407-coronavirus-occitanie-fermeture-frontiere-espagneventes-cigarettes-explosent-cote-francais.

Brailovskaia, J., \& Margraf, J. (2021). The relationship between burden caused by coronavirus (Covid-19), addictive social media use, sense of control and anxiety. Computers in Human Behavior, 119, 106720. https://doi.org/10.1016/j.chb.2021. 106720.

Brooks, S. K., Webster, R. K., Smith, L. E., Woodland, L., Wessely, S., Greenberg, N., \& Rubin, G. J. (2020). The psychological impact of quarantine and how to reduce it: Rapid review of the evidence. The Lancet, 395(10227), 912-920. https://doi.org/10. 1016/S0140-6736(20)30460-8.

Burhamah, W., AlKhayyat, A., Oroszlányová, M., AlKenane, A., Almansouri, A., Behbehani, M., ... AlSuwaidan, M. (2020). The psychological burden of the COVID-19 pandemic and associated lockdown measures: Experience from 4000 participants. Journal of Affective Disorders, 277, 977-985. https://doi. org/10.1016/j.jad.2020.09.014.

Callinan, S., Smit, K., Mojica-Perez, Y., D’Aquino, S., Moore, D., \& Kuntsche, E. (2021). Shifts in alcohol consumption during the COVID-19 pandemic: Early indications from Australia. Addiction, 116(6), 1381-1388. https://doi.org/10.1111/add. 15275.

Caponnetto, P., Inguscio, L., Saitta, C., Maglia, M., Benfatto, F., \& Polosa, R. (2020). Smoking behavior and psychological dynamics during COVID-19 social distancing and stay-at-home policies: A survey. Health Psychology Research, 8, 9124. https:// doi.org/10.4081/hpr.2020.9124.

Cellini, N., Canale, N., Mioni, G., \& Costa, S. (2020). Changes in sleep pattern, sense of time and digital media use during COVID-19 lockdown in Italy. Journal of Sleep Research, 29(4), e13074. https://doi.org/10.1111/jsr.13074.

Centers for Disease Control and Prevention. (2020). Coronavirus disease 2019 (COVID-19): Stress and coping. Retrieved from https://www.cdc.gov/coronavirus/2019-ncov/about/coping. html.

Compton, W. M., Gfroerer, J., Conway, K. P., \& Finger, M. S. (2014). Unemployment and substance outcomes in the United States 2002-2010. Drug and Alcohol Dependence, 142, 350-353. https://doi.org/10.1016/j.drugalcdep.2014.06.012.

Dumas, T. M., Ellis, W., \& Litt, D. M. (2020). What does adolescent substance use look like during the COVID-19 pandemic? Examining changes in frequency, social contexts, and pandemic-related predictors. Journal of Adolescent Health, 67(3), 354-361. https://doi.org/10.1016/j.jadohealth.2020.06. 018

Faber, M., Ghisletta, A., \& Schmidheiny, K. (2020). Auswirkungen der Corona-Massnahmen auf die Erwerbstätigkeit in der Schweiz [Effects of the Corona measures on employment in Switzerland]. Retrieved from https://wwz.unibas.ch/de/ appliedeconometrics/coronavirus/\#top.

Gmel, G., Holmes, J., \& Studer, J. (2016). Are alcohol outlet densities strongly associated with alcohol-related outcomes? A critical review of recent evidence. Drug and Alcohol Review, 35(1), 40-54. https://doi.org/10.1111/dar.12304.

Gmel, G., Rehm, J., \& Kuntsche, E. (2003). Binge-Trinken in Europa: Definitionen, Epidemiologie und Folgen [Binge drinking in Europe: Definitions, epidemiology, and consequences]. SUCHT, 49(2), 105-116. https://doi.org/10.1024/suc. 2003.49.2.105.

Johannes, N., Vuorre, M., \& Przybylski, A. K. (2021). Video game play is positively correlated with well-being. Royal Society Open Science, 8(2), 202049. https://doi.org/10.1098/rsos.202049.

Johnson, D., Jones, C., Scholes, L., \& Carras, M. (2013). Videogames and wellbeing: a comprehensive review. Melbourne: Young and Well Cooperative Research Centre.

Kaye, L. K., Kowert, R., \& Quinn, S. (2017). The role of social identity and online social capital on psychosocial outcomes in MMO players. Computers in Human Behavior, 74, 215-223. https://doi.org/10.1016/j.chb.2017.04.030.

Király, O., Potenza, M. N., Stein, D. J., King, D. L., Hodgins, D. C., Saunders, J. B., ... Demetrovics, Z. (2020). Preventing problematic internet use during the COVID-19 pandemic: 
Consensus guidance. Comprehensive Psychiatry, 100, 152180. https://doi.org/10.1016/j.comppsych.2020.152180.

Király, O., Tóth, D., Urbán, R., Demetrovics, Z., \& Maraz, A. (2017). Intense video gaming is not essentially problematic. Psychology of Addictive Behaviors, 31(7), 807-817. https://doi. org/10.1037/adb0000316.

La Presse.ca. (2020). Le porno surfe sur le coronavirus [Porn surfing on the coronavirus 2020]. Retrieved from https://www. lapresse.ca/societe/sexualite/202003/17/01-5265069-le-pornosurfe-sur-le-coronavirus.php.

Lau, J. T. F., Yang, X., Pang, E., Tsui, H. Y., Wong, E., \& Wing, Y. K. (2005). SARS-related perceptions in Hong Kong. Emerging Infectious Diseases, 11(3), 417-424. https://doi.org/10.3201/ eid1103.040675.

Lechner, W. V., Laurene, K. R., Patel, S., Anderson, M., Grega, C., \& Kenne, D. R. (2020). Changes in alcohol use as a function of psychological distress and social support following COVID-19 related University closings. Addictive Behaviors, 110, 106527. https://doi.org/10.1016/j.addbeh.2020.106527.

Lemenager, T., Neissner, M., Koopmann, A., Reinhard, I., Georgiadou, E., Müller, A., ... Hillemacher, T. (2021). COVID-19 lockdown restrictions and online media consumption in Germany. International Journal of Environmental REsearch and Public Health, 18(1), 14. https://doi.org/10.3390/ijerph18010014.

Luo, T., Chen, W., \& Liao, Y. (2021). Social media use in China before and during COVID-19: Preliminary results from an online retrospective survey. Journal of Psychiatric Research, 140, 35-38. https://doi.org/10.1016/j.jpsychires.2021.05.057.

Marmet, S., Wicki, M., Gmel, G., Gachoud, C., Daeppen, J.-B., Bertholet, N., \& Studer, J. (2021). The psychological impact of the COVID-19 crisis is higher among young Swiss men with a lower socioeconomic status: Evidence from a cohort study. PloS One, 16(7), e0255050. https://doi.org/10.1371/journal.pone. 0255050.

Marmet, S., Wicki, M., Gmel, G., Gachoud, C., Daeppen, J.-B., Bertholet, N., \& Studer, J. (2021a). The psychological impact of the COVID-19 crisis on young Swiss men participating in a cohort study. Swiss Medical Weekly, 151, w30028. https://doi. org/10.4414/SMW.2021.w30028.

McArdle, J. J. (2009). Latent variable modeling of differences and changes with longitudinal data. Annual Review of Psychology, 60(1), 577-605. https://doi.org/10.1146/annurev.psych.60. 110707.163612 .

Mestre-Bach, G., Blycker, G. R., \& Potenza, M. N. (2020). Pornography use in the setting of the COVID-19 pandemic. Journal of Behavioral Addictions, 9(2), 181-183. https://doi.org/ 10.1556/2006.2020.00015.

Muthén, L. K., \& Muthén, B. O. (1998-2017). Mplus user's guide (8th ed.). Los Angeles, CA: Muthén \& Muthén.

Paschke, K., Austermann, M. I., Simon-Kutscher, K., \& Thomasius, R. (2021). Adolescent gaming and social media usage before and during the COVID-19 pandemic. SUCHT, 67(1), 13-22. https://doi.org/10.1024/0939-5911/a000694.

Perez, M. (2020). Video games are being played at record levels as the coronavirus keeps people indoors. Retrieved from https:// www.forbes.com/sites/mattperez/2020/03/16/video-games-arebeing-played-at-record-levels-as-the-coronavirus-keepspeople-indoors/\#7d1d6d7957ba.
Perez, S. (2020). Report: WhatsApp has seen a $40 \%$ increase in usage due to COVID-19 pandemic. Retrieved from https:// techcrunch.com/2020/03/26/report-whatsapp-has-seen-a-40increase-in-usage-due-to-covid-19-pandemic/.

Rehm, J., Kilian, C., Ferreira-Borges, C., Jernigan, D., Monteiro, M., Parry, C. D. H., .. Manthey, J. (2020). Alcohol use in times of the COVID 19: Implications for monitoring and policy. Drug and Alcohol Review, 39(4), 301-304. https://doi.org/10.1111/ dar. 13074 .

Rehm, J., Taylor, B., \& Room, R. (2006). Global burden of disease from alcohol, illicit drugs and tobacco. Drug and Alcohol Review, 25(6), 503-513. https://doi.org/10.1080/095952306009 44453.

Reinecke, L. (2009). Games and recovery: The use of video and computer games to recuperate from stress and strain. Journal of Media Psychology: Theories, Methods, and Applications, 21(3), 126-142. https://doi.org/10.1027/1864-1105.21.3.126.

Rolland, B., Haesebaert, F., Zante, E., Benyamina, A., \& Haesebaert, J., Franck,N. (2020). Global changes and factors of increase in caloric/salty food, screen, and substance use, during the early COVID-19 containment phase in France: A general population online survey. JMIR Public Health and Surveillance, 6(3), e19630. https://doi.org/10.2196/19630.

Sallie, S. N., Ritou, V. J. E., Bowden-Jones, H., \& Voon, V. (2021). Assessing online gaming and pornography consumption patterns during COVID-19 isolation using an online survey: Highlighting distinct avenues of problematic internet behavior. Addictive Behaviors, 123, 107044. https://doi.org/10.1016/j. addbeh.2021.107044.

Sayette, M. A. (1999). Does drinking reduce stress? Alcohol Research \& Health, 23(4), 250-255.

Scarmozzino, F., \& Visioli, F. (2020). Covid-19 and the subsequent lockdown modified dietary habits of almost half the population in an Italian sample. Foods, 9(5), 675. Retrieved from https:// www.mdpi.com/2304-8158/9/5/675.

Schultz, A. (2020). Keeping our services stable and reliable during the COVID-19 outbreak. Retrieved from https://about.fb.com/ news/2020/03/keeping-our-apps-stable-during-covid-19/.

Shanley, P. (2020). Gaming usage up 75 percent amid coronavirus outbreak, Verizon reports. Retrieved from https://www. hollywoodreporter.com/news/gaming-usage-up-75-percentcoronavirus-outbreak-verizon-reports-1285140.

Sher, K. J., Bartholow, B. D., Peuser, K., Erickson, D. J., \& Wood, M. D. (2007). Stress-response-dampening effects of alcohol: Attention as a mediator and moderator. Journal of Abnormal Psychology, 116(2), 362-377. https://doi.org/10.1037/0021843X.116.2.362.

Sher, K. J., \& Levenson, R. W. (1982). Risk for alcoholism and individual differences in the stress-response-dampening effect of alcohol. Journal of Abnormal Psychology, 91(5), 350-367. https://doi.org/10.1037/0021-843X.91.5.350.

Stanton, R., To, Q. G., Khalesi, S., Williams, S. L., Alley, S. J., Thwaite, T. L., .. Vandelanotte, C. (2020). Depression, anxiety and stress during COVID-19: Associations with changes in physical activity, sleep, tobacco and alcohol use in Australian adults. International Journal of Environmental REsearch and Public Health, 17(11), 4065. Retrieved from https://www.mdpi. com/1660-4601/17/11/4065. 
Studer, J., Marmet, S., Wicki, M., \& Gmel, G. (2019). Cybersex use and problematic cybersex use among young Swiss men: Associations with sociodemographic, sexual, and psychological factors. Journal of Behavioral Addictions, 8(4), 794-803. https:// doi.org/10.1556/2006.8.2019.69.

Swiss Federal Council. (2020a). Coronavirus: Federal Council bans gatherings of more than five people. Retrieved from https:/ www.admin.ch/gov/en/start/documentation/media-releases. msg-id-78513.html.

Swiss Federal Council. (2020b). Coronavirus: Federal Council declares extraordinary "situation" and introduces more stringent measures. Retrieved from https://www.admin.ch/gov/en/start/ documentation/media-releases/media-releases-federal-council. msg-id-78454.html.

Swiss Federal Office of Public Health. (2020). COVID-19 en Suisse [COVID-19 in Switzerland]. Retrieved from https://covid-19schweiz.bagapps.ch/fr-2.html.

Swiss Federal Office of Statistics. (2016). Portrait de la Suisse: Résultats tirés des recensements de la population 2010-2014. [Portrait of Switzerland: Results from population censuses 20102014]. Retrieved from Neuchâtel: https://www.bfs.admin.ch/ bfsstatic/dam/assets/1021365/master.

Taylor, S., Paluszek, M. M., Rachor, G. S., McKay, D., \& Asmundson, G. J. G. (2021). Substance use and abuse, COVID19-related distress, and disregard for social distancing: A network analysis. Addictive Behaviors, 114, 106754. https://doi. org/10.1016/j.addbeh.2020.106754.

Vanderbruggen, N., Matthys, F., Van Laere, S., Zeeuws, D., Santermans, L., Van den Ameele, S., \& Crunelle, C. L. (2020). Selfreported alcohol, tobacco, and cannabis use during COVID-19 lockdown measures: Results from a web-based survey.
European Addiction Research, 26, 309-315. https://doi.org/10. 1159/000510822.

Wechsler, H., Davenport, A., Dowdall, G., Moeykens, B., \& Castillo, S. (1994). Health and behavioral consequences of binge drinking in college: A national survey of students at $140 \mathrm{cam}$ puses. JAMA, 272(21), 1672-1677. https://doi.org/10.1001/ jama.1994.03520210056032.

Wilson, A. (2020). Alcohol sales spike as consumers stockpile amid COVID-19 pandemic. Retrieved from https://www.fooddive. $\mathrm{com} /$ news/alcohol-sales-spike-as-consumers-stockpile-duringcoronavirus-pandemic/575331/.

World Health Organization (WHO). (2003). Summary table of SARS cases by country, 1 November 2002-7 August 2003. Retrieved from https://apps.who.int/iris/handle/10665/232250.

World Health Organization (WHO). (2020). WHO coronavirus disease (COVID-19) Dashboard. Retrieved from https:// covid19.who.int/table.

Wu, P., Liu, X., Fang, Y., Fan, B., Fuller, C. J., Guan, Z., . . Litvak, I. J. (2008). Alcohol abuse/dependence symptoms among hospital employees exposed to a SARS outbreak. Alcohol and Alcoholism, 43(6), 706-712. https://doi.org/10.1093/alcalc/agn073\% JAlcoholandAlcoholism.

Zhao, N., \& Zhou, G. (2021). COVID-19 stress and addictive social media use (SMU): Mediating role of active use and social media flow. Frontiers in Psychiatry, 12(85). https://doi.org/10.3389/ fpsyt.2021.635546.

Zobel, F., Esseiva, P., Udrisard, R., \& Samitca, S. (2020). Le marché des stupéfiants dans le canton de Vaud : Les cannabinoïdes [The narcotics market in the canton of Vaud: Cannabinoids]. Retrieved from Lausanne: https://www.addictionsuisse.ch/fileadmin/user_ upload/DocUpload/Rapport-Marstup-3_Cannabinoides_2020.pdf. 